\title{
Correspondence: "How researchers can help fight climate change in 2022 and beyond (Nature)"
}

This editorial adopted a cornucopian position, i.e., human ingenuity and market modification are the solutions to cope with climate change. Authors suggested that research priorities should focus on technological innovation regarding batteries, cars, and renewable energy. However, despite major research efforts in these areas in the past 30 years, $\mathrm{CO}_{2 \mathrm{eq}}$ emissions are still rising.

Major $\mathrm{CO}_{2 \mathrm{eq}}$ emitter countries have to reduce their respective emission by $5 \%$ each year to achieve the Paris agreement and limit global warming to around $2^{\circ} \mathrm{C}$. In concrete terms, high-income countries have to reduce their household energy use by $73 \%$, and reduce their motor vehicle ownership by $96 \%{ }^{1}$. It is highly unlikely that technological innovation alone will solve this issue; this focus further ignores that efficiency gains are often counterbalanced by negative behavioural rebound effects ${ }^{2}$. Efforts should be concentrated on promoting sustainable lifestyles in high-income countries: "a cluster of habits and patterns of behaviour embedded in a society and facilitated by institutions, norms and infrastructures"3. Focusing only on technological solutions to reduce the $\mathrm{CO}_{2 \mathrm{eq}}$ emissions is ineffective. Climate change issues rest on inequalities within and between countries, but also on intergenerational inequalities. Social and psychological sciences will be key to accelerate changes in organizations, laws, social relationships and individual behaviours. This contrasts with just $0.12 \%$ of all research funding spent in social sciences for climate mitigation ${ }^{4}$.

Technological promises are delaying successful climate change mitigation strategies and there is little time left. Social and psychological sciences are needed to accelerate combined individual and structural sustainable changes.

Signed by Paquito Bernard ${ }^{1}$, Guillaume Chevance $^{2}$, Laura König ${ }^{3}$, Vera Araújo-Soares ${ }^{4}$

1. Moore, J. Ecological Footprints and Lifestyle Archetypes: Exploring Dimensions of Consumption and the Transformation Needed to Achieve Urban Sustainability. Sustainability 7, 4747-4763 (2015).

2. Sorrell, S., Gatersleben, B. \& Druckman, A. The limits of energy sufficiency: A review of the evidence for rebound effects and negative spillovers from behavioural change. Energy Research \& Social Science 64, 101439 (2020).

3. Akenji, L., Lettenmeier, M., Koide, R., Toivio, V. \& Amellina, A. 1.5-Degree Lifestyles: Targets and options for reducing lifestyle carbon footprints. (2019).

4. Overland, I. \& Sovacool, B. K. The misallocation of climate research funding. Energy Research \& Social Science 62, 101349 (2020). 
${ }^{1}$ Department of Physical Activity Sciences, Université du Québec, Faculté des Sciences, 141 avenue Président Kennedy, H2X1Y4, Montréal, Québec, Canada.Email: bernard.paquito@uqam.ca. https://orcid.org/0000-0003-2180-9135, . Telephone: +1 5149873000 \#3606

${ }^{2}$ ISGlobal, Barcelona Institute for Global Health, Carrer del Rosselló, 132, 08036, Barcelona, Spain. Email: guillaume.chevance@,isglobal.org,https://orcid.org/0000-0002-8926-4816,

${ }^{3}$ Faculty of Life Sciences, University of Bayreuth, Bayreuth, Germany, , Fritz-Hornschuch-Straße 13, 95326 Kulmbach, Germany. Email: laura.koenig@uni-bayreuth.de, https://orcid.org/0000-0003-3655$\underline{8842}$.

${ }^{4}$ Health Technology and Services Research, University of Twente, Enschede, Technical Medical Centre (Technohal), room 3303, Hallenweg 5, 7522 NH Enschede, The Netherlands. Email: vera.araujosoares@utwente.nl, https://orcid.org/0000-0003-4044-2527. 